\title{
Development of an amperometric screen-printed galactose biosensor for cell toxicity applications
}

\author{
Prosper Kanyong ${ }^{\mathrm{a}}$, Gareth Hughes ${ }^{\mathrm{a}}$, Roy M. Pemberton ${ }^{\mathrm{a}}$, Simon K. Jackson ${ }^{\mathrm{b}}$, \\ John P. Hart ${ }^{\text {a: }}$ \\ ${ }^{\text {a }}$ Centre for Research in Biosciences, Faculty of Health and Life Sciences, University of the West of England, \\ Frenchay Campus, Bristol, BS16 1QY, UK \\ ${ }^{\mathrm{b}}$ Centre for Research in Translational Biomedicine, School of Biomedical and Biological Sciences, University of \\ Plymouth, Plymouth PL4 8AA, UK \\ †Corresponding author- John.Hart@uwe.ac.uk; Tel.: +44 1173282469
}

\begin{abstract}
This paper describes the development and application of a biosensor for the amperometric measurement of galactose, in the presence of human hepatocellular carcinoma cells, with and without the presence of a hepatotoxic agent. The biosensor was fabricated by first drop-coating $1.5 \%$ cellulose acetate onto a 3 x $3 \mathrm{~mm}$ screenprinted carbon electrode. This was followed by depositing $2 \mathrm{U}$ of galactose oxidase. Using gloss finish paint and a valox card to define the electrode area, the dimensions were reduced to $3 \mathrm{~mm} \times 0.5 \mathrm{~mm}$. Hepatocellular carcinoma cells were utilised for in vitro toxicity testing, by evaluating the effect of paracetamol on galactose uptake. The amperometric responses to galactose indicated that the level of inhibition of uptake was directly proportional to the concentration of paracetamol after 24 hours of exposure to the hepatocellular carcinoma cells. These results demonstrate that the fabricated biosensor may be used for the real-time monitoring cell metabolism and toxicity testing.
\end{abstract}




\section{Introduction}

There is a considerable interest in using cell-based assays, ie. experiments based on the use of live cells, for screening the toxicity of chemical compounds, particularly in the pharmaceutical industry. These include a variety of techniques for measuring cell proliferation, morphology, viability, cytotoxicity, and motility (Keese and Giaever 1994; Riss, O'Brien and Morvec 2003; Nabhan 2003). Whereas cell viability assays generally involve measuring the number of live cells, cytotoxicity assays tend to evaluate the number of dead cells. Both types of cell-based assay are routinely used for drug discovery using high-throughput screening, environmental assessment of relevant chemical compounds, and as biosensors for cellular behaviour analysis (Ehret et al 1997; White 2000; Shuileabhain et al 2004). In 2003, Nabhan discovered that over $30 \%$ of prospective candidate drugs fail toxic verification. Consequently, cytotoxicity testing in different cell types has become one of the fundamental tools for drug discovery (Riss, O'Brien and Morvec 2003; White 2000). Hepatotoxicity is a major concern in drug testing as most toxic effects observed are by drugs that are metabolised by the liver; thus liver cells have been utilised by many drug discovery and development laboratories (Anderson et al 1996; Li et al 1999; Ni et al 2001; Valentin et al 2001).

Cultured hepatocytes are routinely used to evaluate the toxicity of chemical compounds (Groneberg, Grosse-Siestrup and Fischer, 2002; Gomez-Lechon, Castell and Donato 2007; Horii and Yamada 2007). Hepatocellular carcinoma cells have been used to screen complex mixtures, in addition to screening individual chemical compounds for potential hepatotoxic effects. Assays using these cells have been used successfully to provide data for determining potential mechanisms of liver 
toxicity (Kelly and Sussman 2000; Flynn and Ferguson 2008; Li and Chan 2009; Prot 2011).

Hepatotoxicity screening methods commonly used include the adenosine triphosphate assay, the 3-[4,5-dimethylthiazol-2-yl]-2,5-diphenyl-tetrazolium bromide assay and the neutral red dye uptake assay (Li et al 1999; Ni et al 2001; Valentin et al 2001; Groneberg, Grosse-Siestrup and Fischer (2002). However, nearly all of such traditional biochemical techniques are laborious, time consuming and tend to involve complex procedures with multiple reagents. For in vitro experiments these techniques are incapable of providing quantitative data without affecting the target cells. This makes it extraordinarily difficult to monitor continuous toxic effects or to analyse real-time changes in cell viability. Consequently, numerous research studies have focused on developing alternative methods that allow for continuous monitoring of toxic effects (Wolf et al 1998; Wegener, Janshoff and Galla 1998; Wegener et al 1999; Wegener, Keese and Giaever 2000; Sohn et al 2000; Phelps and Depaola 2000; Xiao et al 2002; Xiao and Luong 2003).

An alternative electrochemical analytical approach, based on amperometric measurements using fabricated electrodes, may provide the ideal method for detecting hepatotoxicity with multiple reagents. The possibility of obtaining useful metabolic data from cell-based assays in conjunction with amperometry has been recently investigated by our group (Pemberton et al 2009; 2010). In these studies, electrochemical microband biosensors incorporating a relevant enzyme, were successfully utilised to continuously and selectively monitor glucose or lactate. The biosensors could maintain steady-state current responses under quiescent solution conditions and could operate in culture medium for batch-type analysis to monitor 
the depletion of glucose by hepatocytes in a cell density-dependent manner (Pemberton et al 2011). The ability to sustain amperometric current responses over several hours provides the possibility of utilising the biosensors for real-time toxicity monitoring.

Numerous methods for the fabrication of electrodes have been developed and this has led to the manufacture of miniaturised, reproducible and inexpensive devices. Among these, the method of screen-printing is well-documented (Wring and Hart 1992). Screen-printing is a low-cost process, particularly when carbon ink is used, and it has been widely utilised to manufacture electrodes for developing biosensors. The screen-printing process is simple, fast and allows for the printing of electrodes with different geometries (Wring and Hart 1992). In the present paper, galactose biosensors were fabricated, designed and developed utilising a water-based carbon ink formulation. The formulation and the first part of the procedure have been described previously for the fabrication of macroelectrode galactose biosensors for use in serum analysis (Kanyong et al 2013). The present paper describes a modified procedure for the fabrication of microband galactose biosensors. The ability to obtain steady-state responses in quiescent phosphate buffer solutions was investigated using these biosensors. The operation of the galactose biosensor was also investigated in culture medium. Further studies, utilising the galactose biosensor, were conducted to detect the uptake of galactose by the mammalian hepatocellular carcinoma liver cell line at $37^{\circ} \mathrm{C}$, over a period of 24 hours. The effect of paracetamol, a model hepatotoxic compound, on galactose uptake by hepatocellular carcinoma cells was investigated. The results of this study and potential application in toxicity monitoring are discussed in this paper. 


\section{Materials and methods}

\section{Chemical and reagents}

All chemicals including acetone, sodium chloride, high-glucose (4.5 g/L)supplemented Dulbecco's Modified Eagle's medium (DMEM, D5796-500ML), penicillin and streptomycin sulphate were of analytical grade, purchased from Sigma Aldrich, Dorset, UK. $50 \mathrm{mM}$ phosphate buffer was prepared by combining appropriate amounts of tri-sodium phosphate dodecahydrate, sodium dihydrogen orthophosphate dehydrate and disodium hydrogen orthophosphate dehydrate to yield the desired pH. Cellulose acetate (Catalogue number: 3782; LOT: 29F0024), D-(+)galactose (Lot\#: 021M00041V, Code: 1001033250) and galactose oxidase (G7400, from Dactylium dendroides), were obtained from Sigma Aldrich, Dorset, UK. Fetal Bovine Serum (Cat \#: S1810-500; Lot \#: S06015S1810) was purchased from Biosera, East Sussex, UK and stored in small aliquots at $-22{ }^{\circ} \mathrm{C}$. White gloss finish paint and brush were purchased from B\&Q, Avon, UK. Cellulose acetate was dissolved in acetone following up to 2 minutes sonication.

\section{Hepatocellular carcinoma cell culture}

The hepatoma cell line, HepG2, (obtained from the European Collection of Animal Cell Cultures) was cultured as a monolayer in $75 \mathrm{~cm}^{2}$ flasks in a $5 \% \mathrm{CO}_{2}$-in-air atmosphere at $37^{\circ} \mathrm{C}$ with an initial density of $10^{5}$ cells $/ \mathrm{ml}$ in $15 \mathrm{ml}$ of medium. The medium was high-glucose DMEM containing $10 \%$ foetal bovine serum, $1 \%$ nonessential amino acids, $2 \mathrm{mM}$ L-glutamine and $100 \mathrm{U} / \mathrm{ml}$ penicillin and $100 \mu \mathrm{g} / \mathrm{ml}$ streptomycin (pen + strep). When the cells were confluent, known concentrations of galactose and paracetamol were added to the flasks, which were then incubated for a further $24 \mathrm{hr}$. 


\section{Apparatus and measurements}

All electrochemical measurements were conducted with a three-electrode system, consisting of a cobalt phthalocyanine screen printed working electrode (GEM code: C40511D8), Ag/AgCl reference electrode (GEM Product Code: C61003P7) both screen-printed onto valox (a semi-crystalline material based on polybutylene terephthalate and polyethylene terephthalate polymers; Cadillac Plastics Ltd. Swindon, UK) and a separate Pt wire counter electrode. The area of the working electrode was defined using insulating tape (RS, Northants, UK) to define a $3 \times 3$ mm square area.

The working and reference electrodes were connected to the potentiostat with gold clips. An Autolab Electrochemical Analyser with General-Purpose Electrochemical Software (Version 4.9, Netherlands) was used for the acquisition of data and experimental control, with a $10 \mathrm{ml}$ electrochemical cell inside a water jacket for electrochemical measurements. Data was further analysed with Microsoft Excel. Weighing was carried out with a Precisa precision balance 262SMA-FR purchased from Milton Keynes, Buckinghamshire, UK. Measurement and monitoring of $\mathrm{pH}$ was conducted with a Fisherbrand Hydrus 400 pH Meter (Orion Research Inc., USA). Sonications were performed with a Devon FS100 sonicating water bath (Ultrasonics, Hove, Sussex, UK). The temperature was controlled with a thermostated water bath (Thermo Scientific HAAKE DC10-P5/U unit). The dimensions of the valox card were measured using a TESA micrometer obtained from Radio Spares, Switzerland.

\section{Procedures}

\section{Biosensor preparation:}




\section{(i) Immobilization of reagents onto the working area of a cobalt phthalocyanine screen printed working electrode}

The base unmodified cobalt phthalocyanine screen-printed electrode transducer was prepared using a water-based ink and the sensors were screen-printed in groups of six onto valox as previously described by Crouch et al (2005). The cobalt phthalocyanine screen printed electrode was modified by drop-coating $5 \mu$ of $1 \%$ cellulose acetate in acetone directly onto the exposed $9.0 \mathrm{~mm}^{2}$ working electrode and allowed to dry. The electrodes were then coated with $5 \mu 1$ of galactose oxidase solution containing the appropriate number of units and left to air-dry. Dummy biosensors were prepared using the same procedure, except that the enzyme was substituted for the same mass of bovine serum albumin (BSA), as described previously (Kanyong et al 2013).

\section{(ii) Definition of a microband working electrode area}

After drying, the side of a valox card with dimensions of $18 \mathrm{~mm}$ x $500 \mu \mathrm{m}$ was carefully vertically fixed onto the working area of the electrode with an adhesive. White gloss finish paint was then drop-coated onto the working surface to cover the enzyme layer to each side of the vertically fixed valox card and allowed to dry. Once dry, the valox card was carefully removed to expose a $3 \mathrm{~mm}$ x $500 \mu \mathrm{m}$ working electrode area. A schematic of the final biosensor is shown in Figure 1.

Once prepared, the galactose biosensors were stored at $4{ }^{\circ} \mathrm{C}$ in a vacuum desiccator containing silica gel, until ready for use. The same procedure was used to obtain dummy biosensors, by using the same mass of BSA as that of the enzyme; any responses resulting from these devices were subtracted from the biosensor response. 


\section{Calibration studies by amperometry in standard solutions}

Calibration plots for the proposed galactose biosensor were obtained by immersing the electrode in $10 \mathrm{ml}$ of $50 \mathrm{mM}$ phosphate buffer solution containing $50 \mathrm{mM} \mathrm{NaCl}$, or $10 \mathrm{ml}$ DMEM for subsequent tests. A potential of $+0.5 \mathrm{~V}$ vs. $\mathrm{Ag} / \mathrm{AgCl}$ was applied to the working electrode and the system was left for the current response to reach steady-state. Using a micropipette, a series of small additions of standard galactose solution was made, awaiting steady-state responses between additions. Calibration plots were constructed by plotting each current response against the final cell galactose concentration. Mean current responses of three replicates were calculated.

\section{Evaluation of the toxic effect of paracetamol on galactose uptake by hepatocellular carcinoma cells}

A ten millimolar $(10 \mathrm{mM})$ concentration of galactose and either $5 \mu \mathrm{M}, 50 \mu \mathrm{M}, 500$ $\mu \mathrm{M}$ or $1000 \mu \mathrm{M}$ concentrations of paracetamol were incubated in flasks with $15 \mathrm{ml}$ of DMEM containing hepatocellular carcinoma cells for 24 hours. At the start of the experiments, each culture medium contained $10 \mathrm{mM}$ galactose. After the 24-hr incubation period, the current responses due to remaining galactose were measured by amperometry using the galactose and dummy biosensors in quiescent solution. Any responses resulting from the dummy electrode devices were subtracted from the biosensor response. Consequently, the uptake of galactose following the 24-hr incubation period could be estimated. The current responses obtained at 8000 seconds were used to describe the uptake of galactose by the cells as well as the inhibition of galactose uptake by paracetamol. 


\section{Results and Discussion}

\section{Sequences of reactions in the operation of the galactose biosensor}

The analytical response for galactose occurs as a result of the enzymatic and electrocatalytic processes. Hydrogen peroxide is generated during the enzymatic conversion of galactose to D-galacto-hexodialdose in the presence of galactose oxidase and oxygen. Hydrogen peroxide is electrocatalytically oxidised at the cobalt phthalocyanine screen printed electrode, which constitutes the analytical response. This response is directly proportional to the original concentration of galactose.

\section{Calibration studies by amperometry in standard solutions}

The effects of enzyme loading (1.2 - $3 \mathrm{U})$, temperature (25 - $40 \mathrm{C}), \mathrm{pH}(5.0$ - 10.0), the ionic buffer strength $(0.025-0.45 \mathrm{mM})$ on the analytical performance of the biosensor have previously been published (Kanyong et al, 2013). The optimal biosensor performance occurred with a loading of $2 \mathrm{U}$ of galactose oxidase, at $35^{\circ} \mathrm{C}$, $50 \mathrm{mM}$ phosphate buffer ( $\mathrm{pH}$ 7.0). Calibration studies were performed with the optimised galactose over the concentration range of $1.98 \mathrm{mM}-9.52 \mathrm{mM}$ in phosphate buffer solution under quiescent conditions. A fresh biosensor was used with each measurement which was performed in triplicate for each galactose concentration.

As can be seen from the amperometric responses shown in Figure 2, each galactose addition elicited a rapid current response. A calibration study was conducted over a wide concentration range $(1.98-18.18 \mathrm{mM})$ and from this plot, the linear range was observed to be between 1.98 and $9.52 \mathrm{mM}$. The limit of detection based on $\mathrm{S} / \mathrm{N}=3$, 
gave a value of $0.2 \mathrm{mM}$. The biosensor response exhibited a sensitivity of 7.267 $\mu \mathrm{AmM}^{-1} \mathrm{~cm}^{-2}$ with a linear range up to $9.52 \mathrm{mM}$ and a precision (coefficient of variation; CV) for replicate biosensors of $1.3 \%$ in buffer solution. These performance characteristics demonstrate that the galactose biosensor is able to give concentration dependent, steady-state current responses in quiescent solutions.

Consequently, the biosensor performance was then evaluated in culture medium

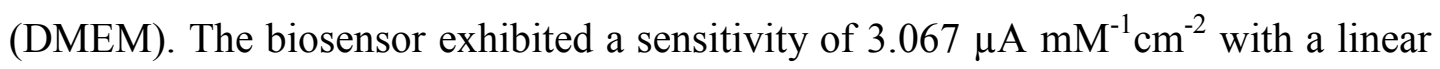
range up to $9.52 \mathrm{mM}$ and a precision $(\mathrm{CV})$ for replicate biosensors of $1.2 \%$. Clearly, the sensitivity of the galactose biosensor in culture medium has been reduced by $\sim 50$ $\%$ of its sensitivity in buffer solution. However, its overall analytical performance in culture medium was considered satisfactory for end-point measurements of galactose in culture medium.

\section{Evaluation of the toxic effect of paracetamol on galactose uptake by hepatocellular carcinoma cells}

The biosensor's ability to measure galactose uptake in cell culture was examined using cell culture supernatants obtained from hepatocellular carcinoma cells. The cells were incubated in $15 \mathrm{mls}$ of culture media containing $10 \mathrm{mM}$ galactose and varying concentrations $(5,50,500$ or $1000 \mu \mathrm{M})$ of paracetamol for 24 hours.

It is well known that cells use glucose as their primary source of energy. It is also worth noting that the depletion of glucose by healthy cells occurs most rapidly during the first 4 hours of growth and continues up to about 10 hours (Pemberton et al 2011). In the absence of glucose, it is expected that the cells would begin to deplete the $10 \mathrm{mM}$ galactose that was added to the culture medium. As can be seen in Figure 3, there was complete galactose uptake by the hepatocellular carcinoma 
cells in the absence of paracetamol. The current of $90 \mathrm{nA}$ for $10 \mathrm{mM}$ galactose was reduced to baseline levels after the $24 \mathrm{~h}$ period, indicating that all of the galactose had been consumed by the cells. An estimate of galactose consumption over $24 \mathrm{~h}$, based on initial cell numbers present, indicates uptake of 150 micromoles by $1.5 \times 10^{6}$ cells, or 100 picomoles of galactose per cell. In the presence of paracetamol, galactose current responses were reduced, indicating inhibition of cell uptake. Paracetamol toxicity appeared to be dose-dependent as shown in Fig.3. In the presence of paracetamol at $1000,500,50$ and $5 \mu \mathrm{M}$, galactose uptake was inhibited by $99 \%, 60 \%, 20 \%$ and $12 \%$ respectively. Similar inhibition of glucose uptake was observed in the presence of $1000 \mu \mathrm{M}$ paracetamol by Pemberton et al. (2011) using a glucose biosensor.

\section{Conclusions}

An amperometric galactose biosensor was developed and characterised in both phosphate buffer and culture medium. In culture medium, the galactose biosensor exhibited a sensitivity of $7.2 \mu \mathrm{AmM}^{-1} \mathrm{~cm}^{-2}$, a linear range up to $9.52 \mathrm{mM}$ and a $\mathrm{CV}$ of $1.2 \%$. This performance was considered satisfactory in evaluating the effect of paracetamol, a model hepatotoxic compound, on galactose uptake by hepatocellular carcinoma cells. Paracetamol toxicity appeared to be dose-dependent and these findings correlate with inhibition profiles observed by Xu, Ma and Purcell (2003) for glucose uptake in the presence of $1000 \mu \mathrm{M}$ paracetamol. This suggests that the amperometric galactose biosensor could be used for real-time monitoring of galactose metabolism to provide additional information on metabolic events. In the future, an array system incorporating screen-printed microelectrode biosensors for a variety of biomarkers, in a multi-well configuration, would be a viable option for 
mammalian cell toxicity testing. The latter has the additional potential for the replacement or reduction of animal testing.

\section{Acknowledgement}

The authors thank the University of the West of England, Bristol for funding. Gwent Electronic Materials are thanked for supplying the screen printed electrodes. 


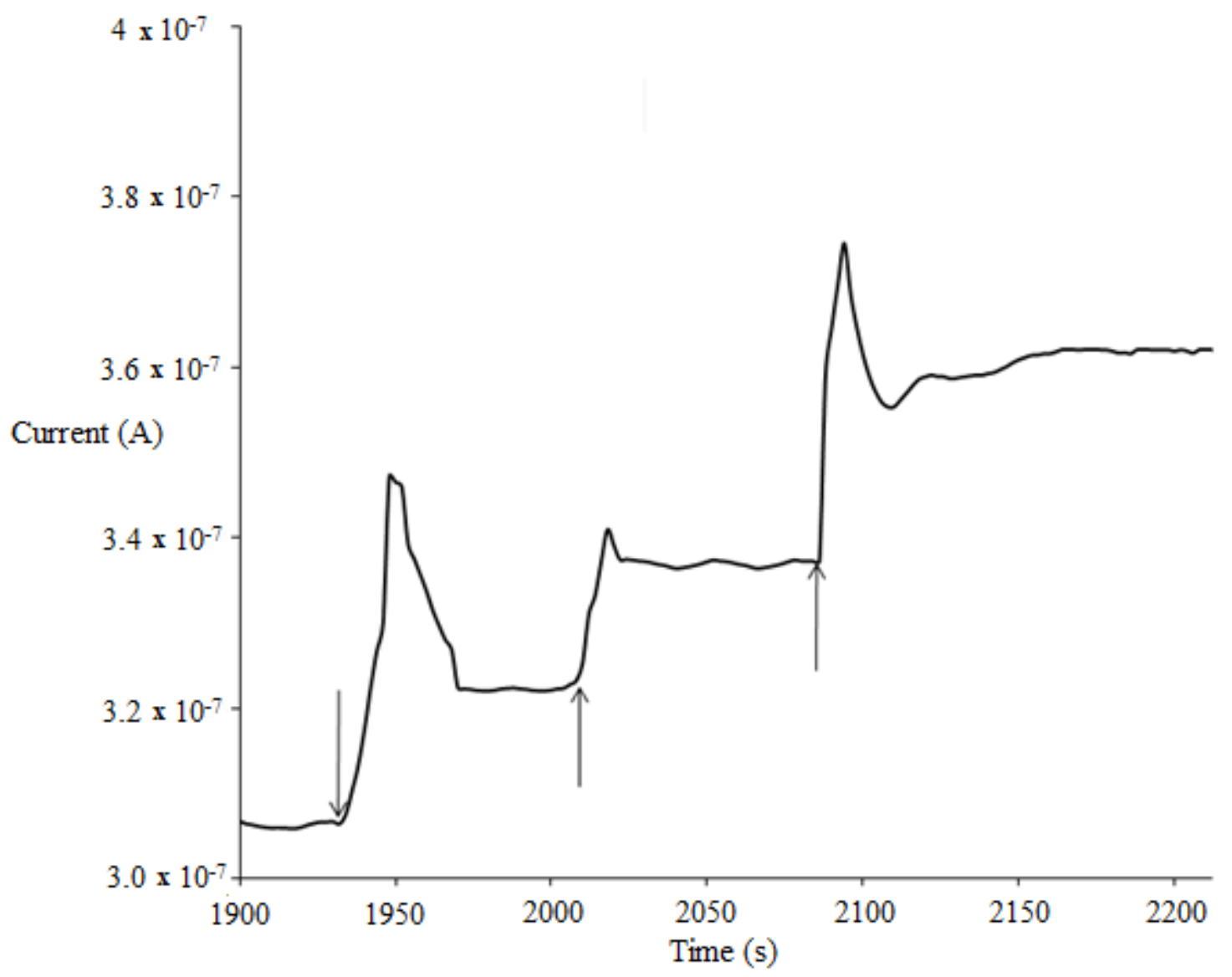

Figure One 


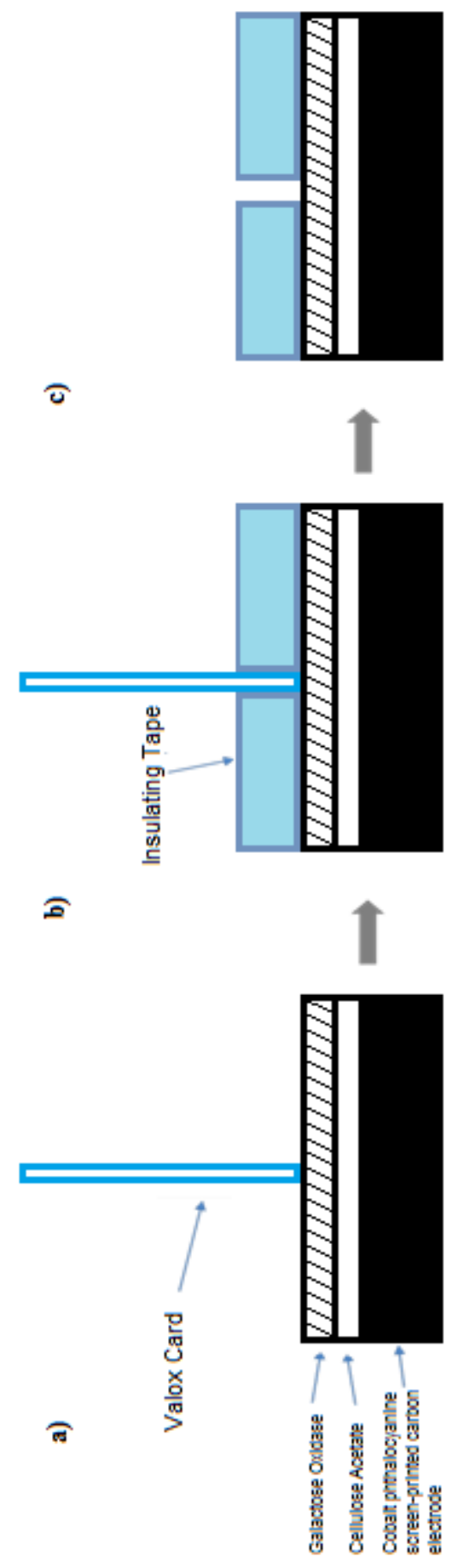

Figure Two 


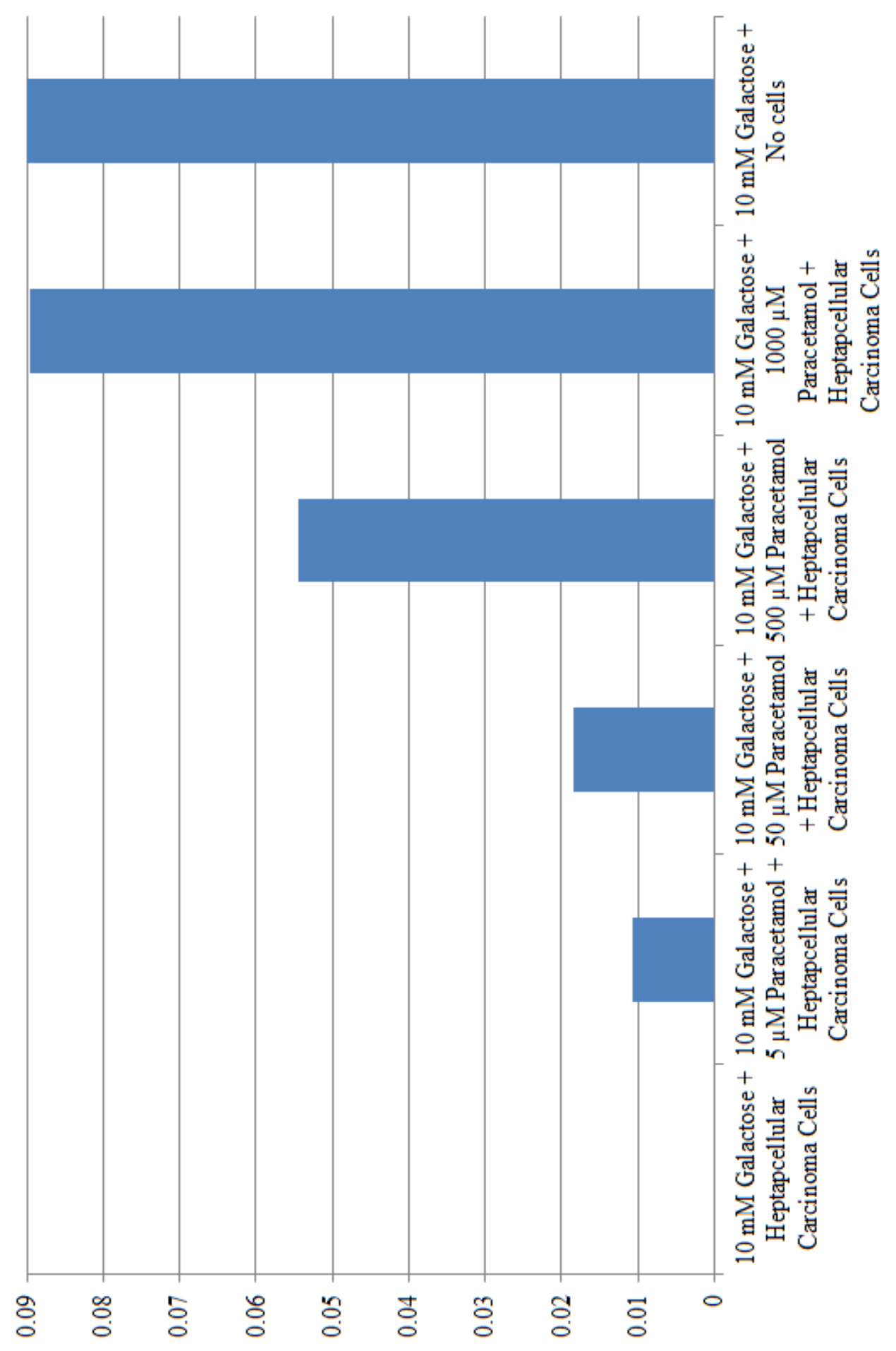

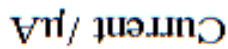

Figure Three 


\section{References}

Anderson, K., Yin, L., Macdonald, C., Grant, M. H. 1996. Immortalized hepatocytes as in vitro model systems for toxicity screening: the comparative toxicity of menodione in immortalized cells, primary cultures of hepatocytes and HTC hepatoma cells. Toxicol. In Vitro 10:721-727.

Crouch, E., Cowell, D. C., Hoskins, S., Pittson, W. P., Hart, J. P. 2005. A novel, disposable, screen-printed amperometric biosensor for glucose in serum fabricated using a water-based carbon ink. Biosens. Bioelectron. 21:712-718.

Ehret, R., Baumann, W., Brischwein, M., Schwinde, A., Stegbaauer, K., Wolf, B. 1997. Monitoring of cellular behavior by impedance measurements on interdigitated electrode structures. Biosens. Bioelectron. 12 (1997) 29-41.

Flynn, T. J., Ferguson, M. S. 2008. Multiendpoint mechanistic profiling of hepatotoxicants in HepG2/C3A human hepatoma cells and novel statistical approaches for development of a prediction model for acute hepatotoxicity. Toxicol. In Vitro 22:1618-1631.

Groneberg, D. A., Grosse-Siestrup, C., Fischer, A. 2002. In vitro models to study hepatotoxicity. Toxicol. Pathol. 30:394-399.

Gomez-Lechon, M. J., Castell, J. V., Donato, M. T. 2007. Hepatocytes- the choice to investigate drug metabolism and toxicity in man: in vitro variability as a reflection of in vivo. Chem. Biol. Interact. 168:30-50.

Horii, I., Yamada, H. 2007. In vitro hepatotoxicity testing in the early phase of drug discovery. Altern. Animal Test. Experimen.14:437-441.

Kanyong, P., Pemberton, R.M., Jackson, S.K. and Hart, J.P. 2013. Development of an amperometric screen-printed galactose biosensor for serum analysis. Anal.Biochem. 435: 114-119.

Keese, C. R., Giaever, I. 1994. A biosensor that monitors cell morphology with electrical fields, IEEE Eng. Med. Biol.: 402-408.

Kelly, J. H., Sussman, N. L. 2000. A fluorescent cell-based assay for cytochrome P450 isozyme 1A2 induction and inhibition. J. Biomol. Screen. 5:249-254.

Li, A. P., Lu, C., Brent, J. A., Pham, C., Fackett, A., Ruegg, C. E., Siber, P. M.1999. Cryopresserved human hepatocytes; characterization of drug-metabolizing enzyme activities and applications in higher throughput screening assays for hepatotoxicity, metabolic stability, and drug-drug interaction potential. Chem. Biol. Interact. 121:17-35.

Li, Z., Chan, C. 2009. Systems biology for identifying liver cytotoxicity pathways, BMC Proc. 3 (Suppl 2):S2.

Nabhan, J. D. A. 2003. Cell-based assays; commercial opportunities, legal trends and technology analyses, D \& MD Report \#9116, D \& MD publication. 
Ni, R., Leo, M.A., Zhao, J., Lieber, C. S. 2001. Toxicity of $\beta$-carotene and its exacerbation by acetyldehyde in HepG2 cells. Alcohol Alcoholism 36:281-285.

Pemberton, R. M., Rawson, F. J., Xu, J., Pittson, R., Drago, G. A., Griffiths, J., Jackson, S. K., Hart, J. P. 2010. Application of screen-printed microband biosensors incorporated with cells to monitor metabolic effects of potential environmental toxins. Microchim. Acta 170:321-330.

Pemberton, R. M., Xu, J., Pittson, R., Biddle, N., Drago, G. A., Jackson, S. K., Hart, J. P. 2009. Application of screen-printed microband biosensors to end-point measurements of glucose and cell numbers in HepG2 cell culture. Anal. Biochem. 285:334-341.

Pemberton, R. M., Xu, J., Pittson, R., Drago, G. A., Griffiths, J., Jackson, S. K., Hart, J. P. 2011. A screen-printed microband glucose biosensor system for real-time monitoring of toxicity in cell culture. Biosens. Bioelectron. 26:2448-2453.

Prot, J. M., Aninat, C., Griscom, L., Razan, F., Brochot, C., Guillouzo, C. G., Legallais, C., Corlu, A., Leclerc, E. 2011. Improvement of HepG2/C3a cell functions in a microfluidic biochip, Biotenol. Bioeng. 108:1704-1715.

Phelps, J. E., Depaola, N. 2000. Spatial variations in endothelial barrier function in disturbed flows in vitro. Am. J. Physiol. Heart Circ. Physiol. 278:469-476.

Riss, T., O'Brien, M., Morvec, R. 2003. Choosing the right cell-based assay for your research. Cell Notes 6:6-12.

Shuileabhain, S. N., Mothersill, C., Sheehan, D., O'brien, N. M., O'Halloran, J., Van Pelt, F. N. A. M., Davoren, M. 2004. In vitro cytotoxicity testing of three zinc metal salts using established fish cell lines. Toxicol. In Vitro 18:365-376.

Sohn, L. L., Saleh, O. A., Facer, G. R., Beavis, A. J., Allan, R. S., Notterman, D. A. 2000. Capacitance cytometry: measuring biological cells one by one. Proc. Natl. Acad. Sci. USA 97:1687-1690.

Valentin, I., Phillippe, M., Lhuguenot, J. C., Chagnon, M. C. 2001. Uridine uptake inhibition as a cytotoxicity test for a human hepatoma cell line (HepG2 cells): comparison with the neural red assay. Toxicol. 158:127-139.

White, R. E. 2000. High-throughput screening in drug metabolism and pharmacokinetic support of drug discovery. Annu. Rev. Pharmacol.Toxicol.40:133157.

Wolf, B., Brischwein, M., Baumann, W., Ehret, R., Kraus, M. 1998. Monitoring of cellular signaling and metabolism with modular sensor-technique: the physiocontrolmicrosystem (PCM). Biosens. Bioelectron. 13:501-509.

Wegener, J., Janshoff, A., Galla, H. J. 1998. Cell adhesion monitoring using a quartz crystal microbalance: comparative analysis of different mammalian cell lines. Eur. Biophys. J. 28:26-37.

Wegener, J., Zink, S., Rosen, P., Galla, H. J. 1999. Use of electrochemical impedance measurements to monitor $\beta$-adrenergic stimulation of bovine aortic endothelial cells. Eur. J. Physiol. 437:925-934. 
Wegener, J., Keese, C. R., Giaever, I. 2000. Electric cell-substrate impedance sensing (ECIS) as a noninvasive means to monitor the kinetics of cell spreading to artificial surfaces. Exp. Cell Res. 259: 158-166.

Wring, S. A., Hart, J. P. 1992. Chemically modified screen-printed carbon electrodes. Analyst 117: 1281-1286.

Xiao, C., Lachance, B., Sunahara, G., Luong, J. H. T. 2002. Assessment of cytotoxicity using electric cell-substrate impedance sensing: concentrations and time response function approach. Anal. Chem. 74:5748-5753.

Xiao, C., Luong, J. H. T. 2003. On line monitoring of cell growth and cytotoxicity using electric cell-substrate impedance sensing (ECIS). Biotechnol. Prog. 19:10001005 .

Xu, J., Ma, M., Purcell, W. M. 2003. Characterization of some cytotoxic endpoints using rat liver and HepG2 spheroids as in vitro models and their application in hepatotoxicity studies. I. Glucose metabolism and enzyme release as cytotoxic markers. Tox. Appl. Pharma. 189:100-111.

\section{Figure Captions}

Figure 1: Schematic representation of the proposed galactose biosensor.

Figure 2: Typical amperometric responses obtained with the galactose biosensor on exposure to various concentrations of standard galactose solutions: $1.98,4.88$ and 9.52 respectively in unstirred $10 \mathrm{ml}$ of $50 \mathrm{mM}$ phosphate buffer solution $(\mathrm{pH} 7.0)$ containing $50 \mathrm{mM} \mathrm{NaCl}$ at an applied potential of $+0.5 \mathrm{~V}$.The arrows show the points at which additions of galactose are made to the cell.

Figure 3: Bar graph illustrates the current responses for each of the 24-hr supernatants obtained from cell cultures containing HepG2 cells in $15 \mathrm{ml}$ volumes and incubated with $10 \mathrm{mM}$ galactose and either 5, 50, 500 or $1000 \mu \mathrm{M}$ paracetamol. 
